\title{
O TRABALHO DE CAMPO NA FORMAÇÃO DO TÉCNICO EM MEIO AMBIENTE
}

\author{
João Victor Pavesi de Oliveira ${ }^{1}$
}

Neste artigo apresentamos um breve relato de uma das experiências de trabalho de campo realizadas com os estudantes do $3^{\circ}$ ano do Ensino Técnico em Meio Ambiente Integrado ao Ensino Médio da ETEC - Parque da Juventude. Em novembro de 2015, visitamos o Jardim Pantanal (São Paulo/SP) como atividade escolar na disciplina de Uso, Ocupação e Conservação do Solo (UOCS). Após descrever a proposta da disciplina e o intuito do trabalho de campo, narramos a vivência obtida no bairro da zona leste, fundamentando a importância do campo na formação profissional e acadêmica dos estudantes. Com isso, pretendemos impulsionar a continuidade de atividade escolares como esta.

\section{Introdução}

De acordo com o "Catálogo de Requisitos de Titulação para Docência"2, a disciplina de UOCS, oferecida ao último ano do ETIM em Meio Ambiente, pode ser ministrada por bacharéis e licenciados em Geografia, dentre outros profissionais. Tendo ciência de que eu atendia a esses critérios, a escola me ofereceu a oportunidade de lecioná-la no ano letivo de 2015.

Ao ler a apresentação da competência disciplinar no plano de curso $^{3}$, notei que a função dessa matéria era tratar dos "Processos de degradação natural e avaliação das intervenções antrópicas", tendo em suas competências "Analisar a ocupação do solo no espaço rural e urbano, em nível local, regional e mundial”. Desse modo, sendo eu um estudioso das questões urbanas, focado no debate sobre o direito à cidade, elaborei um Plano de Trabalho Docente que contemplasse tal ementa, com dois momentos: um primeiro, que considera o movimento histórico de ocupação do solo no Brasil, destacando a formação das cidades (com enfoque para São Paulo) e apontando seus desdobramentos ambientais como produto do processo de produção do espaço urbano; um segundo, que trata da legislação urbana e ambiental. Dessa forma, seria possível realizar, ao final do curso, uma avaliação usando um estudo de caso.

Devido a minha formação, parti de categorias analíticas do pensamento urbano advindas da ciência geográfica para realizar uma interpretação da problemática urbano-ambiental. Também foram utilizados materiais de consulta, além da própria legislação específica ${ }^{4}$ e comentadores, em especial autores do pensamento urbano crítico ${ }^{5}$. Pretendia-se, com isso, que os estudantes reconhecessem que a ação da sociedade produz, no modo de produção capitalista, um espaço urbano marcado por conflitos e desigualdades socioespaciais, e que compreendessem como a legislação ambiental e urbana são produto destas mesmas contradições.

Nesse sentido, apreender uma realidade urbana tão complexa e essencialmente conflituosa somente no interior da sala de aula não era suficiente. Mesmo com a utilização de tecnologias voltadas para o ensino, era necessário ultrapassar os limites da escola para alcançar, de fato, uma compreensão do espaço urbano. Recuperarei, a seguir, os debates sobre o ensino de Geografia para justificar a relevância dos trabalhos de campo.

\footnotetext{
${ }^{1}$ E-mail: joao.pavesi@gmail.com.

${ }^{2}$ Disponível em: <http://www.cpscetec.com.br/crt/>. Acesso em 15 abr. 2017.

${ }^{3}$ Disponível em: <http://www.etecparquedajuventude.com.br/Cursos/Etim/MeioAmbiente/PlanoCurso/167\%20\%20ETIM\%20Meio\%20Ambiente\%202015.pdf>. Acesso em 15 abr. 2017.

${ }^{4}$ Novo Código Florestal (Lei 12.651/2012) e Plano Diretor Estratégico de São Paulo (Lei 16.050/2014).

${ }^{5}$ SANTOS, 2008; CARLOS, 1992; HARVEY, 2013; ROULNIK, 1988.
} 
Diferentes geógrafos apresentam proposições acerca da relevância da vivência empírica. Apenas para citar alguns, Paul Vidal de La Blache (1982, p. 47) afirmava que "A Geografia é a ciência dos lugares e não dos homens", apontando a importância nas "excursões geográficas", para melhor observar, analisar e descrever o conjunto da superfície da Terra. Já Pierre Monbeig (1957, p. 31-32), como outros autores de seu tempo, assinalava que a Geografia deveria estar atenta também aos homens e suas relações sociais, deixando de se restringir somente aos fenômenos naturais. Para tanto, a investigação somente em gabinete por meio de levantamentos bibliográficos, informações estatísticas e governamentais, não era suficiente para entender a realidade social localizada, era preciso também a investigação empírica (o trabalho de campo). Disto, desdobramse importantes debates sobre método da prática dos estudos de campo, dentre os quais Yves Lacoste (2006, p. 77), que reconheceu o caráter político do trabalho de campo, condição que traz responsabilidade ao pesquisador diante de homens e mulheres e do território de análise.

Considerando tais discussões, entendo que o exercício de técnico em Meio Ambiente colocará esse profissional diante de circunstâncias socioambientais complexas e que, portanto, ele não poderá se deixar levar pelo mito da neutralidade científica. Assim, deve-se reconhecer, ainda na formação, que sua atuação será essencialmente uma prática política.

O trabalho de campo, estando situado na relação entre teoria e prática, permite-nos compreender que não existe teoria sem prática e vice-versa. E é por meio desse movimento teóricoprático que se disponibiliza suporte intelectual para os estudantes lidarem com situações complicadas no momento de sua atuação na realidade. Sendo assim, o trabalho de campo corresponde a um instrumento privilegiado para, além de descortinar a realidade social espacializada, conectar teoria com prática e expor a implicação política do técnico em Meio Ambiente.

Devido a isso, ao longo do ano de 2015, foram propostas duas saídas de campo: uma, para região central da cidade, e outra, para um bairro periférico de São Paulo. A primeira pretendia analisar o processo de produção da cidade a partir da sua expressão na Paisagem urbana, percorrendo o triângulo histórico, o "centro novo" e finalizando na Av. Paulista. Esse primeiro campo ocorreu no início do $2^{\circ}$ bimestre e tinha como objetivo contextualizar o recorte analítico proposto pela disciplina, já que todos vivenciam a cidade.

O segundo campo, realizado no $4^{\circ}$ Bimestre, tinha um caráter conclusivo tanto para a disciplina de UOCS quanto para o curso técnico como um todo. O mote da saída era pensarmos sobre o direito à cidade em uma localidade profundamente marcada pelo conflito socioambiental, desconhecida pela maioria dos estudantes. Assim, decidiu-se visitar o Jardim Pantanal acompanhados por moradores que mostrariam, na sua perspectiva, um pouco do cotidiano do bairro.

Como preparação do campo, foram realizadas aulas que contextualizaram a área que seria visitada e disponibilizados um mapa do local, um Roteiro de Campo com orientações para elaboração do relatório, e dois excertos de texto que fundamentavam a seguinte problematização: "A ação do técnico em Meio Ambiente é capaz de efetivar o direito à cidade quando a problemática ambiental é separada da produção do espaço urbano metropolitano?”.

Pretendia-se, com isso, que os estudantes articulassem no relatório os conteúdos estudados ao longo do ensino médio - tanto nas disciplinas técnicas quanto na base curricular comum - discutindo, a partir de levantamento bibliográfico e de relatos do campo, a (im)possibilidade de se desatrelar as questões ambientais dos temas urbanos, que são essencialmente sociais. Ademais, o relatório foi realizado em grupo para que os estudantes tivessem de formular uma síntese contemplando suas diferentes visões sobre a problematização.

A organização da saída de campo teve início com uma reunião com o Coordenador Pedagógico da escola, seguida por um comunicado enviado aos pais e responsáveis dos alunos, o qual pedia que autorizassem sua participação. Com o interesse de não deixar nenhum 
estudante de fora da atividade por questões financeiras - visto que a escola não dispunha de recursos para custear os gastos -, a saída foi organizada com baixo custo: o descolamento foi feito gratuitamente, com transporte público, graças ao passe-livre escolar; e uma cozinheira do bairro foi contratada para fazer marmitas e suco pelo preço de $\mathrm{R} \$ 12,00$.

\begin{tabular}{|c|}
\hline \\
\hline $\begin{array}{l}\text { Cronograma } \\
\text { Encontro na escola: } 07 \mathrm{~h} 15 \\
\text { Saída: } 07 \mathrm{~h} 30 \\
\text { Previsão de chegada: } 09 \mathrm{~h} 30 \\
\text { Previsão de término: } 15 \mathrm{~h} 00 \\
\text { Retorno na escola: } 17 \mathrm{~h} 00\end{array}$ \\
\hline $\begin{array}{l}\text { Custo } \\
\text { Transporte + almoço (R\$12,00) }\end{array}$ \\
\hline $\begin{array}{l}\text { Materiais } \\
\text { Instrumentos de campo (caderneta, máquina } \\
\text { fotográfica, gravador etc.); água, biscoitos e } \\
\text { frutas durante a caminhada; } \\
\text { prato+talheres+caneca não descartáveis; } \\
\text { proteção contra chuva e Sol. }\end{array}$ \\
\hline
\end{tabular}

Quadro 01: Orientações para trabalho de campo

\section{O campo}

Saímos da escola, localizada em Santana, na zona norte, e pegamos o metrô na estação Carandiru (Linha 1 - Azul) rumo à estação de trem Jardim Helena - Vila Mara (Linha 12 Safira). A opção por esse meio de transporte, além de ser mais barata, oferecia aos estudantes a experiência de vivenciar a relação centro-periferia (ao menos, no aspecto distância), comum para boa parte da população de São Paulo. Mais do que isso, no percurso realizado pelo trem, saindo da estação Brás na região central e indo em direção a Calmon Viana (bairro da cidade de Poá), pudemos ver velhos galpões industriais, moradias autoconstruídas na linha férrea, e as curvas do rio Tietê, o que não seria possível por outro meio de transporte. Desse modo, o início do trabalho de campo se deu assim que nos encontramos na escola, onde já começava a leitura e a interpretação da Paisagem e suas características espaciais. 
JARDIM PANTANAL - ZONA LESTE (SÃO PAULO/SP)

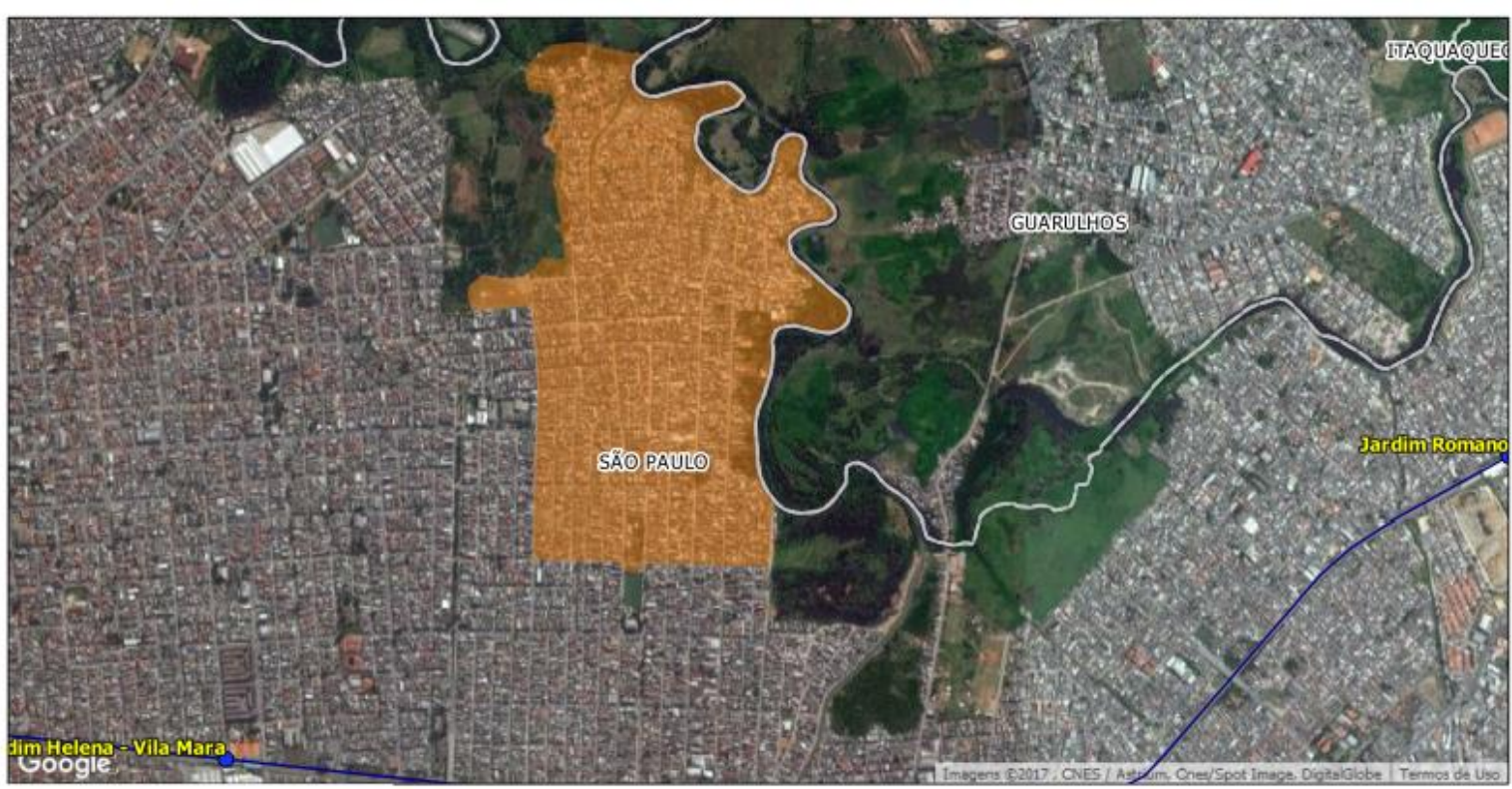

Legenda

- Estações de trem

- Linha de trem - СРTM

Limite dos municípios da RMSP Jardim Pantanal

Google Satellite
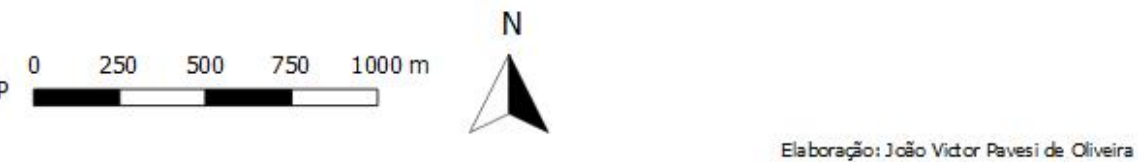

Mapa 01: Localização do Jardim Pantanal

O Jardim Pantanal está localizado na periferia Leste de São Paulo, na conurbação entre os municípios de Guarulhos e Itaquaquecetuba. Situado à margem do rio Tietê, em uma área de proteção ambiental (APA Várzeas do Tietê), o bairro é produto do processo de segregação socioespacial, com ausência de equipamentos públicos, ocupação em áreas irregulares, população de baixa renda, loteamentos clandestinos, entre outros aspectos que caracterizam a maior parte dos bairros periféricos espalhados pelas grandes metrópoles. Seu nome se deve ao fato de ser uma área frequentemente alagada pelo transbordamento do rio Tietê.

Ao chegarmos ao local, encontramos os moradores que nos acompanhariam pelo dia e começamos nossa caminhada, ouvindo relatos sobre a formação do bairro e histórias que o marcaram. Estabelecido por volta de 1986 por migrantes e população pauperizada na busca de moradia digna, o Jardim Pantanal foi a última área ocupada da região entre Ermelino Matarazzo e Itaim Paulista, processo que teve início em meados dos anos 1970. Entre 1988 e 1993, o bairro teve um grande crescimento, chegando a ter aproximadamente 6.000 famílias ao longo das margens do Tietê. 


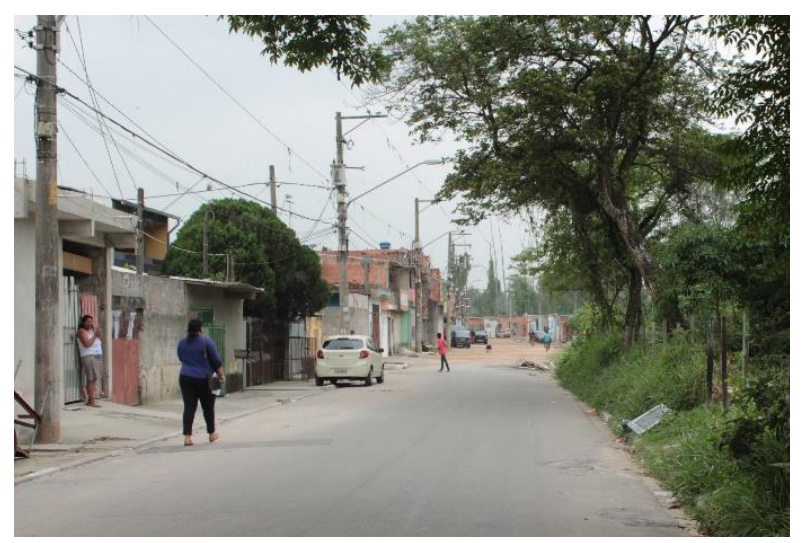

Foto 01: Rua asfaltada



Foto 03: Encanamento exposto

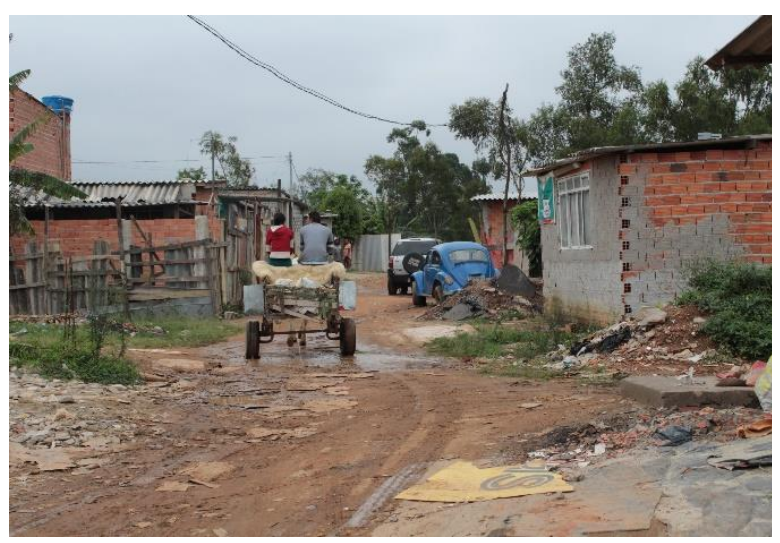

Foto 02: Rua com solo exposto



Foto 04: Moradia à margem do rio

Rapidamente, foi notado que nem todas as ruas eram asfaltadas, somente aquelas de ocupação mais antiga, mais distantes do rio. Esse aspecto chamou atenção dos estudantes, o que produziu a sensação de terem "saído de São Paulo" devido à ausência do concreto, à distância percorrida, à inexistência de prédios e à quantidade de vegetação.

Na parte mais próxima ao rio, a SABESP não implementava saneamento básico a fim de não estimular a ocupação das várzeas. Por causa da ausência de água e esgoto tratados, a comunidade veio a construir um sistema de distribuição de água potável (foto 03) para as moradias, utilizando a rede de água da rua. Contraditoriamente, a empresa distribuidora de luz fez questão de garantir que todas as casas possuíssem ponto de energia, evitando que ocorressem os conhecidos gatos.

As moradias nessa parte eram as mais recentes exatamente por estarem em uma área proibida para construções e, com isso, serem frequentemente removidas pela ação da Polícia Militar, Guarda Ambiental e outros agentes públicos. Além disso, devido à recorrência das enchentes, havia a contínua construção de novas casas. Ouvimos relatos de que é comum moradores erguerem seus armários e utensílios domésticos para evitar prejuízos no período de chuvas. Mesmo sabendo dos riscos de se estabelecerem tão próximos ao rio (remoção forçada, problemas de saúde e perdas materiais), a área sempre estava ocupada.

É a partir dessas narrativas que se revelou o cotidiano das pessoas residentes no Jardim Pantanal. Com elas, foi possível elucidar a dimensão escalar do fenômeno da urbanização, pois, ao reconhecer que áreas distantes entre si (bairros nobres e periferias afastadas) estão intimamente conectadas, evidenciou-se que a problemática social e ambiental não se restringe à escala do local, dando novos contornos ao entendimento da questão urbana. 
Cabe citarmos uma situação referente ao despejo irregular de entulho na margem do Tietê por um morador do bairro que causou muito impacto nos estudantes. A situação ganhou destaque, pois, após os alunos se depararem com a irregularidade e fazerem diversas articulações mentais entre o conhecimento técnico e os efeitos daquela ação, houve a oportunidade de eles conversarem com o sujeito do despejo incorreto. Esse momento promoveu o encontro conflituoso entre as elaborações teóricas e a realidade definida pela problemática social. Aquele sujeito realizava tal ação não por desprezo à natureza, mas por ser esta a forma encontrada para conseguir sobreviver. Assim, em vez de julgá-lo, os estudantes perceberam a necessidade de contextualizar sua condição.

Esta ocasião evidenciou o caráter político do profissional técnico em Meio Ambiente e retomou a problemática apresentada no roteiro de campo, já que a aplicação das normativas ambientais não seria suficiente para solucionar a questão.

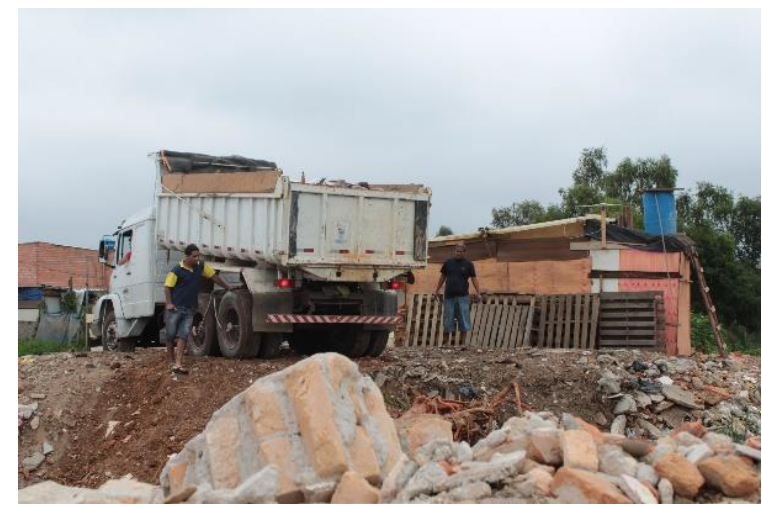

Foto 05: Despejo ilegal de entulho

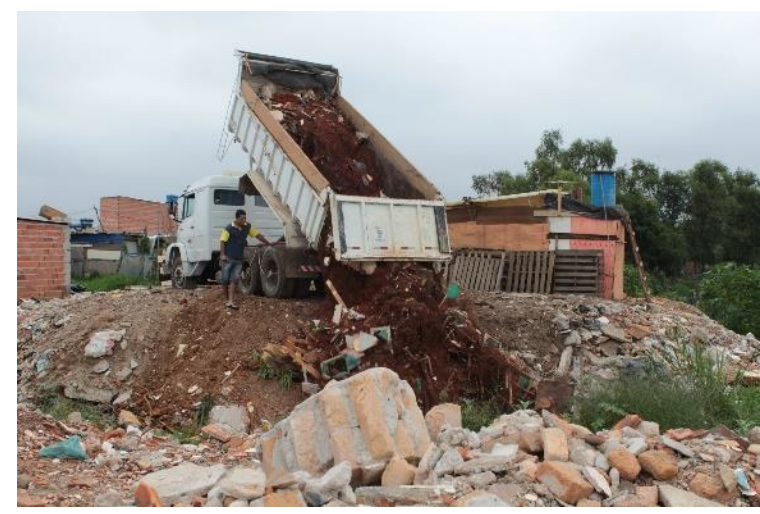

Foto 07: Despejo ilegal de entulho



Foto 06: Despejo ilegal de entulho

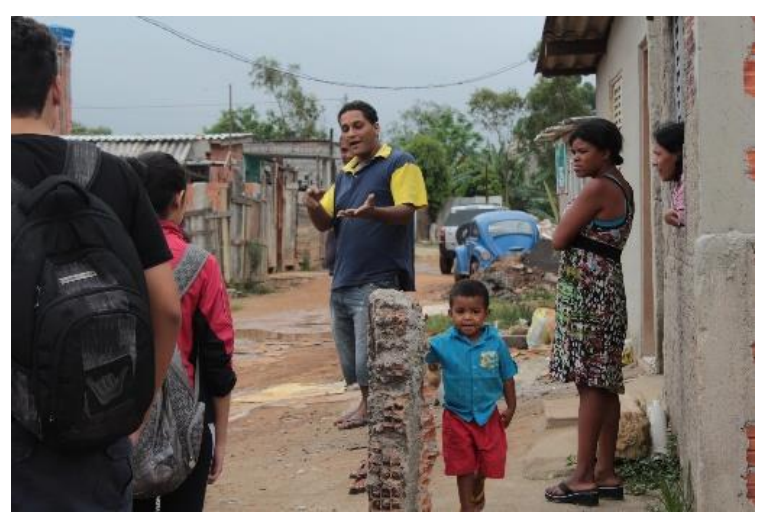

Foto 08: Conversa com moradores

\section{Conclusão}

Com esse breve relato, busquei demonstrar a importância para a realização de trabalhos de campo no curso técnico em Meio Ambiente. Mais do que uma metodologia educativa inovadora, por utilizar outros ambientes que não só a sala de aula, as saídas de campo proporcionam uma experiência particular para esses estudantes ao coloca-los em contato com realidades complexas nas relações socioambientais.

A formação consistente de um técnico em Meio Ambiente ultrapassa o domínio da legislação, o uso adequado de metodologias laboratoriais e a elaboração de planos ambientais. É necessário que se vivencie, na prática, a teoria aprendida em aulas e leituras. 
Infelizmente, essa história não terá mais continuidade no ETIM de Meio Ambiente da ETEC - Pq. da Juventude. Para o ano letivo de 2017, de forma pouco transparente, foi definida a não abertura de vagas para este curso, interrompendo uma história sem uma justificativa concreta.

Esperamos que esse relato motive professoras(es) a realizarem trabalhos de campos em suas disciplinas, oferecendo uma formação ampla e de qualidade que ultrapassa os aspectos profissionais.



Foto 09: Grupo de estudantes e moradores no final do trabalho de campo ${ }^{6}$

\section{Referências}

CARLOS, A. F. A. A cidade. São Paulo: Ed. Contexto, 1992.

HARVEY, D. A liberdade da cidade. In: MARICATO, Ermínia et al. Cidades Rebeldes - Passe livre e as manifestações que tomaram as ruas do Brasil. 1. ed. São Paulo: Boitempo, Carta Maior, 2013. p. 27-34.

LA BLACHE, P. V. “As características próprias da Geografia”. In: CHRISTOFOLETTI, A. Perspectiva da Geografia. São Paulo: Difel, 1982, p. 37-48.

LACOSTE, Y. A pesquisa e o trabalho de campo: um problema político para os pesquisadores, estudantes e cidadãos. Boletim Paulista de Geografia/Seção São Paulo - Associação dos Geógrafos Brasileiros, v. 84, 2006. p. 77-92.

MONBEIG, P. Novos estudos de Geografia Humana brasileira. São Paulo: Difusão Europeia do Livro, 1957.

\footnotetext{
${ }^{6}$ Dedico este trabalho a todos os participantes desta saída de campo.
} 
O TRABALHO DE CAMPO NA FORMAÇÃO DO TÉCNICO EM MEIO AMBIENTE

ROULNIK, R. O que é a cidade. São Paulo: Ed. Brasiliense, 1988

SANTOS, M. Manual de Geografia Urbana. São Paulo: Edusp, 2008. 